\title{
La internacionalización del
} derecho constitucional en Colombia: una garantía para los procesos de integración. Ejercicio comparado con los países andinos*

\author{
Internationalization of constitutional \\ law in Colombia: a guarantee for the \\ processes of integration. Exercise compared \\ with andean countries
}

Eric Tremolada Álvarez**

\section{RESUMEN}

Este escrito, desde la perspectiva del derecho internacional, aborda el estudio comparado de la internacionalización del derecho constitucional en Colombia como garantía de los procesos de integración. De ahi que parta del análisis del ordenamiento internacional como una unidad formal compuesto por tres estructuras normativas, para luego centrarse en el estudio de la internacionalización del ordenamiento colombiano. En particular se constata cómo este orden interno recibe y ejecuta el derecho internacional y cómo garantiza sus obligaciones respecto a los procesos de integración. Finaliza con un ejercicio

\begin{abstract}
This paper, from the perspective of international law, addresses the comparative study of the internationalization of constitutional law in Colombia as a guarantee for the integration processes. Hence, it departs from the analysis of the international legal system performing as a formal unit composed of three normative structures.

It focuses then on the study of internationalization of Colombian law - noting in particular- how this internal order receives and executes international law and how it guarantees its obligations regarding integration processes. It ends its review with a comparative exercise
\end{abstract}

\footnotetext{
* Recibido: 30 de junio de 2015. Aceptado: 11 de agosto de 2015.

** Titular en Colombia de la Cátedra Jean Monnet de Derecho de la Integración Comparado: Unión Europea América Latina en la Universidad Externado. (eric.tremolada@uexternado.edu.co)
} 
comparado de las cláusulas de apertura y control democrático, que en materia de integración se observa en los paises andinos.

PALABRAS CLAVE: Ordenamiento internacional, internacionalización del derecho constitucional colombiano, garantías constitucionales en materia de integración, cláusulas constitucionales de apertura, recepción y control democrático en los países andinos. of the clauses of openness and democratic control -that in terms of integration - have been observed in the Andean countries.

KEY WORDS: International order, internationalization of Colombian constitutional law, constitutional guarantees in terms of integration, clauses of constitutional openness, reception and democratic control in the Andean countries.

\section{SUMARIO}

1. Introducción

2. El ordenamiento internacional: tres ámbitos de relaciones en una unidad formal

3. El ordenamiento colombiano y su internacionalización

a) Recepción de normas consuetudinarias

b) Recepción de normas convencionales

c) Ejecución de normas internacionales en Colombia

4. La internacionalización del derecho constitucional como garante de los procesos de integración

5. Cláusulas constitucionales de apertura y control democrático en los paises andinos

6. Conclusiones

\section{Introducción}

El constitucionalismo internacional surge a la par con el fenómeno de la globalización, fundamentalmente para atemperar su carácter avasallador y evitar que se imponga el poder económico al político. Meir sostiene que esto 104 es gracias a la concepción racionalista de los derechos humanos como posición preferente a los poderes político (autoritarismo) y económico (globalización), que en muchos casos son ilimitados, sin más contención que el voluntarismo de los Estados y los vaivenes caprichosos del capital global. ${ }^{1}$

Así, se revaluó el Estadocentrismo (dependencia de la persona con respecto al Estado), afirmando el principio de dignidad del ser humano y su primacía

\footnotetext{
${ }^{1}$ Meter Garcia, Eduardo. "(Neo) Constitucionalismo e internacionalización de los derechos", Universitas. Revista de Filosofia, Derecho y Politica, No. 15, 2012, pp. 27-64.
} 
(posición preferente de sus derechos). La dignidad de la persona y el respeto universal de los derechos humanos y de las libertades fundamentales fueron proclamados en la Carta de San Francisco como propósitos fundamentales de la Organización de las Naciones Unidas y del derecho internacional de los derechos humanos. Inició un proceso de transformación del derecho internacional clásico.

En palabras de Ansuátegui, la dignidad del ser humano y su primacía encontraron en la democracia un marco natural sobre el cual edificarse. El único poder capaz de vincularse con la moralidad de los derechos y, por ende, con el volumen y las exigencias de esa ética mínima, es el poder político democrático. Así, la democracia adquiere sentido a partir del respeto de las exigencias individuales de los seres humanos. ${ }^{2}$

Desde la Constitución de Weimar en 1919, se inició el reconocimiento constitucional del derecho internacional como parte integrante del derecho interno. Dicha situación - por lo que anotamos- progresó notablemente en la segunda posguerra en tres sentidos: el reconocimiento amplio de la primacía del derecho internacional general, la creación del derecho comunitario (o, como luego ha sido denominado, derecho de la integración), y el respeto al derecho internacional de los derechos humanos. ${ }^{3}$

De esta manera, el aplacamiento surgido del constitucionalismo internacional determina aquellas "tendencias y procesos que están haciendo del mundo un lugar más interdependiente", como Twining define globalización, ${ }^{4}$ y los procesos en virtud de los cuales "los estados nacionales soberanos se entremezclan e imbrican mediante actores transnacionales y sus respectivas posibilidades de poder, orientaciones y entramados varios", lo que la globalización significa en términos de Beck. ${ }^{5}$ De ahí que Ramírez Cleves hablara de las transformaciones del constitucionalismo en el contexto de la globalización que es, en últimas, de lo que se trata este escrito. ${ }^{6}$

Para abordar el estudio de la internacionalización del derecho constitucional en Colombia desde la perspectiva de la integración -sin omitir el sesgo ius internacionalista del autor- necesitamos, en primer lugar, comprender el funcionamiento del ordenamiento internacional como una unidad formal compuesta

\footnotetext{
${ }^{2}$ Ansuátegul Roig, Francisco Javier. "La Declaración Universal de Derechos Humanos y la ética pública", en Garcia Rodríguez, Luis Fernando (Coord.), Estudios en homenaje al 60 aniversario de la Declaración Universal de los Derechos Humanos (1948-2008), Fundación Universitaria de Derecho, Administración y Política, México, 2008, pp. 21-41.

${ }^{3}$ Fix-ZAmudio, Héctor. "El derecho internacional de los derechos humanos en las constituciones latinoamericanas y en la Corte Interamericana de Derechos Humanos", Revista Latinoamericana de Derecho, No. 1, 2004, pp. 141-180.

${ }^{4}$ Twining, Willam. Derecho y globalización, Universidad de los Andes, Bogotá, 2003, p. 120.

${ }^{5}$ Beck, ULRICH. ¿Qué es la globalización? Paidós, Madrid, 2001, p. 29.

${ }^{6}$ Ramirez Cleves, Gonzalo. "Transformaciones del constitucionalismo en el contexto de la globalización", en El derecho en el contexto de la globalización, Universidad Externado de Colombia, Bogotá, 2007.
} 
por tres estructuras normativas. A partir de ahí, podremos centrarnos en el análisis de la internacionalización del ordenamiento colombiano estudiando, en particular, la forma en que recibe y ejecuta el derecho internacional para luego evidenciar qué tan garantista es nuestro ordenamiento respecto a los procesos de integración como parte del derecho interno.

Esta evolución se da desde el ordenamiento internacional. Sin embargo, no sería posible sin la aprobación de los propios Estados, quienes finalmente consienten las obligaciones, negocian y aprueban los tratados y las resoluciones que impulsan esta dinámica. De ahí la necesidad de analizar las normas constitucionales colombianas de apertura y control democrático, haciendo además un breve ejercicio comparado con nuestros vecinos andinos. Evidenciaremos cómo en esta subregión se ha revaluado el concepto clásico de soberanía que aún permanece en la mayoría de Estados latinoamericanos.

\section{El ordenamiento internacional: tres ámbitos de relaciones en una unidad formal}

El derecho internacional regula la coexistencia de relaciones entre Estados soberanos independientemente de su nivel de poder y desarrollo económico, reglamenta la mutua cooperación y protege ciertos intereses esenciales de la comunidad internacional. Esta definición de González Campos y otros ${ }^{7}$ resalta, tal como ellos precisan, los tres ámbitos de relaciones que guardan correspondencia con las tres estructuras normativas diferenciadas que componen la unidad formal del ordenamiento internacional: soberanía, cooperación y solidaridad. $\mathrm{Al}$ tomar en cuenta que los creadores y los que aseguran la aplicación del derecho internacional son los Estados, no es extraño que este sujeto primario se encuentre en las tres estructuras normativas, ocupando un rol preminente en la comunidad internacional.

No obstante, puede apreciarse que en la primera estructura normativa el Estado actúa libremente, con fundamento en la soberanía, en todo lo que no

106 hay un consenso común. De ahí que el peso del poder político y económico de unos favorezca más la satisfacción del interés propio, obligaciones territoriales, reconocimientos de Estados y de gobiernos beligerantes, entre otros que se dan en esta estructura. ${ }^{8}$ Por el contrario, en los otros dos andamiajes

\footnotetext{
${ }^{7}$ González Campos, Julio, Sánchez Rodriguez, Luis y Sáenz de Santa Maria, Paz Andrés. Curso de derecho internacional público, Civitas Ediciones, Madrid, 2002, pp. 82-87.

${ }^{8}$ En este sentido, tenemos múltiples ejemplos a lo largo de la historia y del desarrollo del derecho internacional. El avistamiento y la conquista fueron cristalizándose como títulos para el ejercicio de las competencias del Estado cuando no habia consenso sobre esto. Los reconocimientos prematuros como nuevos estados a Georgia, Croacia,
} 
normativos, hay una evidente interdependencia: la cooperación presupone la existencia de problemáticas y necesidades comunes. Usualmente se aborda a través de organizaciones interestatales. ${ }^{9}$ Por su parte, la protección de ciertos intereses esenciales limita, en razón de la solidaridad, la actuación del Estado que deberá velar responsablemente por los derechos y libertades fundamentales de la persona, respetar el ejercicio de la autodeterminación de los pueblos y cuidar el medio ambiente humano. ${ }^{10}$

Así, el ordenamiento internacional es un todo, compuesto por tres estructuras normativas que corresponden a los ámbitos de relaciones y que se nutren por sus distintas formas de creación del derecho. Allí el Estado actúa con ventaja por ser el que crea y asegura la ejecución de obligaciones.

\section{El ordenamiento colombiano y su internacionalización}

Colombia, como Estado, participa y está obligado por el ordenamiento internacional a incorporar en su organización estructural el derecho internacional, sin distinguir con claridad en qué ámbito de relaciones se origina y con cuál estructura normativa se corresponde. La preocupación del constituyente del 91 se centró en los procedimientos de recepción del derecho internacional de conformidad con su forma de creación (consuetudinaria o convencional) y en algunos casos también por su contenido (derecho internacional humanitario). ${ }^{11}$

\section{a) Recepción de normas consuetudinarias}

La formación de normas consuetudinarias no se concreta en un acto específico. La costumbre surge de una práctica general, constante y uniforme de los Estados, acompañada de la convicción de obrar conforme a derecho. Por tanto, la integración o recepción de estas normas, debido a su naturaleza, no necesitarían acto formal y específico de incorporación al ordenamiento interno.

Kosovo, efectuados por Estados musculosos, disolvieron la Unión Soviética y Yugoslavia. Más recientemente, encontramos la definición instrumental que muchos Estados hacen del terrorismo o la argumentación colombiana para aplicar el fallo de la Corte Internacional de Justicia en su disputa con Nicaragua.

${ }^{9}$ La consecución de un sistema de seguridad colectiva que garantice paz y seguridad internacionales (de la Organización de Naciones Unidas) y el acceso a mercados seguros y predecibles (regulado en el marco de la Organización Mundial de Comercio) son ejemplos en este sentido.

${ }^{10}$ Unos límites a la actuación del Estado son los sistemas universales y regionales de derechos humanos, o el Título XI de la Carta de Naciones Unidas que, bajo el eufemismo de "Territorios no autónomos", se adelantó al proceso de autodeterminación de los pueblos bajo dominación colonial.

"Salgar, Carlos y Tremolada, Eric. "Soberanía, cooperación y solidaridad: del derecho internacional al derecho interno en Colombia", Cultura Latinoamericana Revista de Estudios Interculturales, año 2012 (I), No. 15, Fondazione ISLA per gli Studi Latinoamericani, Universidad Católica de Colombia, Planeta Colombiana, Bogotá, 2013, pp. 207-236. 
Siguiendo a González, un postulado general admite que el derecho internacional de carácter consuetudinario se integra al derecho interno desde el momento mismo de su formación; por consiguiente, es aplicable por el juez nacional. ${ }^{12}$

En el caso colombiano, la Corte Constitucional recoge el postulado; reconoce la integración del derecho internacional humanitario a la Constitución por vía de las normas internacionales consuetudinarias y por la propia Constitución:

El derecho internacional humanitario ha sido fruto esencialmente de unas prácticas consuetudinarias, que se entienden incorporadas al llamado derecho consuetudinario de los pueblos civilizados. Por ello, la mayoría de los convenios de derecho internacional humanitario deben ser entendidos más como la simple codificación de obligaciones existentes que como la creación de principios y reglas nuevas. Así, esta Corporación, en las sentencias citadas, y en concordancia con la más autorizada doctrina y jurisprudencia internacionales, ha considerado que las normas de derecho internacional humanitario son parte integrante del ius cogens. [...] Esto explica que las normas humanitarias sean obligatorias para los Estados y las partes en conflicto, incluso si estos no han aprobado los tratados respectivos, por cuanto la imperatividad de esta normatividad no deriva del consentimiento de los Estados sino de su carácter consuetudinario [...] La obligatoriedad del derecho internacional humanitario se impone a todas las partes que participen en un conflicto armado, y no sólo a las Fuerzas Armadas de aquellos Estados que hayan ratificado los respectivos tratados. No es pues legítimo que un actor armado irregular, o una fuerza armada estatal, consideren que no tienen que respetar en un conflicto armado las normas mínimas de humanidad, por no haber suscrito estos actores los convenios internacionales respectivos, puesto que la fuerza normativa del derecho internacional humanitario deriva de la universal aceptación de sus contenidos normativos por los pueblos civilizados y de la evidencia de los valores de humanidad que estos instrumentos internacionales recogen. [...] En Colombia no sólo el derecho internacional humanitario es válido en todo tiempo sino que, además, opera una incorporación automática del mismo al ordenamiento interno nacional, lo cual, por lo demás, es lo congruente con el carácter imperativo que, según ya fue explicado, caracteriza a los principios axiológicos que hacen que este cuerpo normativo integre el ius cogens. [...] El bloque de consti-

${ }^{12}$ González Campos, Julio, Sánchez Rodriguez, luis y Sáenz de Santa Maria, Paz Andrés. Op. cit., pp. 273-275. 
tucionalidad está compuesto por aquellas normas y principios que, sin aparecer formalmente en el articulado del texto constitucional, son utilizados como parámetros del control de constitucionalidad de las leyes, por cuanto han sido normativamente integrados a la Constitución, por diversas vías y por mandato de la propia Constitución. ${ }^{13}$

Respecto al denominado bloque de constitucionalidad, ha dicho la misma Corporación:

Las disposiciones que hacen parte del bloque de constitucionalidad ostentan jerarquía constitucional por estar situadas a la altura de las normas del texto de la Carta y forman con él un conjunto normativo de igual rango. El hecho de que las normas que integran el bloque de constitucionalidad tengan jerarquía constitucional hace de ellas verdaderas fuentes de derecho, lo que significa que los jueces en sus providencias y los sujetos de derecho en sus comportamientos oficiales o privados deben atenerse a sus prescripciones. Así como el preámbulo, los principios, valores y reglas constitucionales son obligatorios y de forzoso cumplimiento en el orden interno, las normas del bloque de constitucionalidad son fuente de derecho obligatoria para todos los asociados. ${ }^{14}$

Así, el Estado colombiano debe adaptar las normas de inferior jerarquía del orden jurídico interno a los contenidos del derecho internacional humanitario, con el fin de potenciar la realización material de tales valores.

Todo lo anterior significa que las reglas del derecho internacional humanitario, hoy, por voluntad expresa del constituyente que integra las normas internacionales consuetudinarias, son "normas obligatorias per se sin ratificación alguna previa o sin expedición de norma reglamentaria. Y lo son 'en todo caso' como lo señala significativamente la propia Carta”. ${ }^{15}$

\section{b) Recepción de normas convencionales}

Una comunidad internacional cada vez más interdependiente evidencia la frecuente creación de obligaciones mediante tratados internacionales y la posibilidad de establecer derechos y deberes respecto a los particulares. De ahí

\footnotetext{
${ }^{13}$ Corte Constitucional. Sentencias C-574 de 1992 y C-225 de 1995.

${ }^{14}$ Corte Constitucional. Sentencia C-067 de 2003.

${ }^{15}$ Corte Constitucional. Sentencia C-574 de 1992.
} 
que los ordenamientos internos se ocupen expresamente de la recepción de estas normas a través de diversas técnicas que giran en dos extremos. Una es el régimen de recepción automática, procedimiento que exige la simple publicación del acuerdo internacional, como si se tratara de una norma interna; la otra, el régimen de recepción especial, técnica que necesita un acto legislativo expreso para la incorporación del tratado en el orden interno. ${ }^{16}$ Colombia, a diferencia de muchos países de América y Europa Occidental, como la mayoría de los andinos, Gran Bretaña y algunos otros de la Commonwealth, adoptaron un régimen de recepción especial, haciendo depender la eficacia interna de los tratados celebrados de su transformación en ley.

La cuestión aparece regulada en la Constitución, artículo 150: “Corresponde al Congreso hacer las leyes. Por medio de ellas ejerce las siguientes funciones: [...] 16. Aprobar o improbar los tratados que el Gobierno celebre con otros Estados o con entidades de derecho internacional”. También aparece en el artículo 241.

A la Corte Constitucional se le confía la guarda de la integridad y supremacía de la Constitución, en los estrictos y precisos términos de este artículo. Con tal fin, cumplirá las siguientes funciones: 10. Decidir defınitivamente sobre la exequibilidad de los tratados internacionales y de las leyes que los aprueben. Con tal fin, el Gobierno los remitirá a la Corte, dentro de los seis días siguientes a la sanción de la ley. Cualquier ciudadano podrá intervenir para defender o impugnar su constitucionalidad. [...] Si la Corte los declara constitucionales, el Gobierno podrá efectuar el canje de notas; en caso contrario no serán ratificados. Cuando una o varias normas de un tratado multilateral sean declaradas inexequibles por la Corte Constitucional, el Presidente de la República sólo podrá manifestar el consentimiento formulando la correspondiente reserva.

110 Conviene resaltar que la ley aprobatoria de los tratados cumple con una función de carácter interno (darle un fundamento a los tratados internacionales que se pretenden hacer valer); los tratados en el ámbito internacional están incólumes. No están condicionados a que exista o no un pronunciamiento, bien jurisdiccional o bien legislativo, respecto a ellos, tal como lo ha señalado la Corte Constitucional. ${ }^{17}$

\footnotetext{
${ }^{16}$ Véase Remiro Brotóns, Antonio. Derecho internacional, McGraw-Hill, Madrid, 1997, pp. $356-357$.

${ }^{17}$ Corte Constitucional. Sentencia C-276 de 1993.
} 
Por su parte, la decisión sobre la constitucionalidad de los tratados por parte de la Corte Constitucional no cabe para los tratados perfeccionados antes de la promulgación de la Constitución de 1991, toda vez que su competencia nació de la decisión del constituyente de dicho año. Como podría aplicarse cuando la manifestación del consentimiento estatal ha sido anterior a la instancia de la revisión constitucional:

Se entiende que se pierda la capacidad de juzgamiento interno de los tratados ya perfeccionados, como un reflejo natural de la supranacionalidad en este tipo de convenios que comprometen a la Nación, como persona de derecho público internacional, en un acto en el que ha perfeccionado su voluntad y en donde ningún organismo de carácter interno, ni siquiera el órgano encargado de la jurisdicción constitucional, puede entrar a revisar aquello que es ley entre las partes, siendo tales los Estados vinculados. ${ }^{18}$

El requisito procesal de revisión del contenido de los tratados no se cumple, por cuanto el examen constitucional no se puede ejercer respecto a los instrumentos públicos internacionales ya perfeccionados.

La Carta Política ha tenido en cuenta este espíritu de equivalencia entre las partes, al considerar que el control constitucional tan sólo se puede ejercer con anterioridad al momento en que se perfeccione el Tratado, esto es, previamente a la manifestación íntegra de la voluntad del Estado pactante. ${ }^{19}$

Por su parte, no deja de ser curioso que el constituyente del 91 (el cual construyó una constitución que privilegia la integración desde su preámbulo) no citara los actos de organización internacional como mecanismos de creación del derecho internacional o al menos hiciera alusión a su incorporación automática. Sin embargo, gracias a una nutrida práctica jurisprudencial, suple la ausencia del derecho positivo. Esto es consecuente con su participación en distintas organizaciones internacionales, cuyo texto constitutivo le atribuye la facultad de adoptar actos de contenido obligatorio que pueden afectar en el ordenamiento interno a los derechos y obligaciones de los particulares.

\footnotetext{
${ }^{18}$ Corte Constitucional. Sentencia C-567 de 1993.

${ }^{19}$ Corte Constitucional. Sentencia C-276 de 1993.
} 
$\mathrm{Al}$ respecto, la Corte Constitucional ha señalado:

La evolución del derecho internacional ha dado lugar a la aparición del llamado derecho comunitario, fruto del traslado de competencias normativas específicas de los países suscriptores de un convenio o acuerdo, a los órganos supranacionales creados en el mismo. Este traslado de competencias, al ser ejercidas, da lugar a un conjunto de regulaciones que constituyen propiamente la materia del derecho comunitario, respecto de las cuales se predica la preeminencia y la aplicación preferencial frente al derecho interno de cada país miembro. En virtud de lo anterior, no es posible que la legislación nacional modifique, agregue o suprima normas sobre aspectos regulados por la legislación comunitaria. Podrá desarrollarla, pero esta facultad es excepcional y sólo es posible ejercerla cuando sea necesario para lograr la aplicación de aquella. ${ }^{20}$

Así, el derecho comunitario, surgido como resultado del traslado de competencias en diferentes materias del quehacer normativo de los países miembro y las subsecuentes regulaciones expedidas por las autoridades comunitarias, ofrece la doble característica de un sistema preeminente o de aplicación preferencial frente al derecho interno de cada país miembro y con una capacidad de aplicación directa y de eficacia inmediata. A las regulaciones que se expidan con arreglo al sistema comunitario no es posible oponerle determinaciones nacionales paralelas que regulen materias iguales o que obstaculicen su aplicación, ni su eficacia puede condicionarse a la voluntad del país o de las personas eventualmente afectadas por una decisión.

La integración comunitaria responde y se afianza sobre la concepción moderna de la soberanía relativa, que ya no la reconoce como un poder supremo absoluto e ilimitado del Estado, sino como algo limitado y restringido por la interacción de los demás Estados dentro de la comunidad internacional, lo cual obviamente implica la resignación de específicas competencias de los Estados en organismos comunitarios con el fin de hacer viable los procesos de integración económica. ${ }^{21}$

\footnotetext{
${ }^{20}$ Corte Constitucional. Sentencia C-155 de 1998.

${ }^{21}$ Corte Constitucional. Sentencia C-228 de 1995.
} 


\section{c) Ejecución de normas internacionales en Colombia}

Las normas internacionales, sean de carácter no escrito (como las consuetudinarias) o escrito (como las convencionales o actos de organizaciones interestatales) pueden contener obligaciones de alcance general que afectan las relaciones Estado a Estado. Además, pueden regular directamente derechos y obligaciones concretos para los particulares. A su vez, y respecto a su ejecución, pueden ser directamente aplicables en el orden interno o, por el contrario, necesitarán forzosamente la adopción de actos normativos internos. De ahí la necesidad de examinar las disposiciones que tiene previstas en este sentido el ordenamiento jurídico colombiano. ${ }^{22}$

Las normas que contienen obligaciones de carácter general son directamente aplicables, como habíamos señalado, al derecho internacional general consuetudinario. Desde el momento de su creación, pasa a formar parte del derecho interno sin necesidad de actos específicos de incorporación y, por consiguiente, el juez nacional puede aplicarla. Sin embargo, esta práctica, por generalizada que sea, dependerá en últimas de lo dispuesto a propósito en cada derecho estatal, es decir, de las previsiones particulares en materia de recepción y jerarquía.

En el caso colombiano, la autosuficiencia y la naturaleza autoejecutiva de estas normas está garantizada en la Constitución Política: “el Estado reconoce, sin discriminación alguna, la primacía de los derechos inalienables de la persona" (artículo 5); "las relaciones exteriores de Colombia se fundamentan en el reconocimiento de los principios de Derecho internacional” (artículo 9). Adicionalmente, puede darse una aplicación preferente sobre la propia Constitución y los tratados -siempre que se trate de un tratamiento más favorable-. "La enunciación de los derechos y garantías contenidos en la Constitución y en los convenios internacionales vigentes no debe entenderse como negación de otros que, siendo inherentes a la persona humana, no figuren expresamente en ellos" (artículo 94). A su vez, la Corte Constitucional no ha escatimado pronunciamientos sobre la autosuficiencia y la naturaleza autoejecutiva del derecho internacional general consuetudinario. En especial, nos referiremos a los contenidos en las sentencias C-574 de 1992, C-225 de 1995 y C-067 de 2003, que no dejan duda al respecto. Las obligaciones de carácter general son directamente aplicables en el ordenamiento interno sin necesidad de ningún acto ad hoc:

\footnotetext{
22 Tremolada, Eric. El Derecho Andino en Colombia, Facultad de Finanzas, Gobierno y Relaciones Internacionales Universidad Externado de Colombia, Bogotá, 2006, pp. 102-108.
} 
El derecho internacional humanitario es, ante todo, un catálogo axiológico cuya validez absoluta y universal no depende de su consagración en el ordenamiento positivo. ${ }^{23}$

[Este derecho] ha sido fruto esencialmente de unas prácticas consuetudinarias, que se entienden incorporadas al llamado derecho consuetudinario de los pueblos civilizados. Por ello, la mayoría de los convenios de derecho internacional humanitario deben ser entendidos más como la simple codificación de obligaciones existentes que como la creación de principios y reglas nuevas. ${ }^{24}$

[La imperatividad, validez e incorporación del derecho internacional humanitario] "no deriva del consentimiento de los Estados sino de su carácter consuetudinario", que es "válido en todo tiempo" sino que, además, "opera una incorporación automática del mismo. ${ }^{25}$

[La misma sentencia, delimitó el bloque de constitucionalidad, observando que] está compuesto por aquellas normas y principios que, sin aparecer formalmente en el articulado del texto constitucional, son utilizados como parámetros del control de constitucionalidad de las leyes, por cuanto han sido normativamente integrados a la Constitución, por diversas vías y por mandato de la propia Constitución ${ }^{26}$.

Es claro que si los preceptos, principios y valores contenidos en el bloque de constitucionalidad irradian el texto de la normatividad interna y obligan a las autoridades a acondicionarla a sus disposiciones, también las decisiones judiciales tienen que guardar similar obediencia. Así entonces, no sólo el productor del derecho positivo, sino también el ejecutor de la norma y su intérprete autorizado, están compelidos a seguir los lineamientos del bloque de constitucionalidad, ya que en dicha sumisión reside la validez jurídica de sus actuaciones. ${ }^{27}$

Por su parte, respecto a las normas internacionales de origen convencional que regulan derechos y obligaciones concretos sobre los particulares, necesitan de un mecanismo de recepción que definirá el Estado. En palabras de Dahm, el derecho internacional es obligatorio para los Estados, aunque en principio llega a los individuos, únicamente por medio del derecho estatal. Es decir, exige

\footnotetext{
${ }^{23}$ Corte Constitucional. Sentencia C-574 de 1992.

${ }^{24}$ Corte Constitucional. Sentencia C-225 de 1995.

${ }^{25}$ Ibidem.

${ }^{26}$ Ibidem.

${ }^{27}$ Corte Constitucional. Sentencia C-067 de 2003.
} 
que se cumpla en el derecho interno, pero no dice cómo; deja la elección de la técnica al derecho nacional. ${ }^{28}$

La citada tesis, por un lado, nos ayuda a corroborar el reconocimiento pleno y la constatación de diferentes ordenamientos con validez jurídica sólo para los sujetos de ese orden jurídico; por el otro, nos permite analizar qué sucede cuando las partes en la convención crean derechos y obligaciones sobre los particulares de forma precisa e incondicional.

$\mathrm{Al}$ respecto, el Tribunal Permanente Internacional de Justicia, en su opinión consultiva del 4 de febrero de 1932, en el asunto relativo al tratamiento de los empleados ferroviarios de Dantzig que habían pasado en esta calidad a Polonia en virtud de un tratado, precisó que "un Estado no puede invocar respecto de otro Estado su propia Constitución para sustraerse de las obligaciones que le imponen el derecho internacional o los tratados en vigor". "El acuerdo estaba destinado a regir entre los empleados ferroviarios y Polonia”; es decir, el convenio reconoció derechos a favor de los particulares en forma precisa e incondicional; por tanto, no se requerían medidas normativas de desarrollo. ${ }^{29}$

Una vez incorporadas a los ordenamientos estatales, las normas y las obligaciones internacionales de origen convencional gozarán de aplicación inmediata por los órganos administrativos y judiciales, siempre que no necesiten medidas de desarrollo. La doctrina conoce como normas self-executing a aquellas directamente aplicables al orden interno por contener mandatos que reconocen derechos precisos e incondicionales a favor de los particulares y que son susceptibles de ser ejecutados por las autoridades estatales, sin necesidad de medida legislativa o reglamentaria de desarrollo. ${ }^{30}$

Por otra parte, las normas y obligaciones internacionales que imponen un resultado o que contienen derechos imprecisos y condicionales a favor de los particulares, necesitarán adopción de actos normativos internos. Estas normas conocidas como actos non self-executing abundan en la práctica, sea porque sólo pueden satisfacerse mediante un hacer legislativo y reglamentario (como en el caso de tratados que definen tipos penales), o porque no concretan los requisitos exigibles o el procedimiento para el disfrute de los derechos que contemplan a favor de los particulares (como sucede con el Pacto Internacional de Derechos Económicos, Sociales y Culturales de 1966). ${ }^{31}$

\footnotetext{
${ }^{28}$ Truyol y Serra, Antonio. Fundamentos de derecho internacional público, Tecnos, Madrid, 1977, p. 114.

${ }^{29}$ Tribunal Permanente Internacional de Justicia (TPIJ) Serie A/B, No. 44, p. 24.

${ }^{30}$ Véase Remiro Brotóns, Antonio. Op. cit., p. 364 y González Campos, Julio, Sánchez Rodriguez, luis y Sáenz de Santa Maria, Paz Andrés. Op. cit., p. 289.

${ }^{31}$ Remiro Brotóns, Antonio. Op. cit., p. 365.
} 
En Colombia, como en muchos otros países, la dificultad radica en que la apreciación de la aplicabilidad directa queda en manos de los órganos administrativos o judiciales que no siempre están al tanto de que esta condición proviene, según la técnica de recepción, del propio tratado (automática) o de su ley aprobatoria (especial).

El régimen de recepción especial colombiano implica, para la validez de los tratados, la necesaria aprobación del Congreso a través de una ley, la cual queda sujeta al control de exequibilidad de la Corte Constitucional. ${ }^{32}$ Así, una vez incorporada la norma u obligación internacional en el ordenamiento colombiano mediante una ley, será self-executing siempre que no necesite medida adicional de desarrollo, en tanto que ya reconoce derechos precisos e incondicionales de los particulares; de lo contrario, será non self executing.

Finalmente, en el caso en que las normas y las obligaciones sean actos de organizaciones interestatales, no existe en el ordenamiento colombiano técnica expresa de incorporación, pese a la vocación integracionista de su Constitución. Pero este vacío de positivismo jurídico, tal como ya lo anunciamos, ha sido suplido por una nutrida práctica jurisprudencial. La respuesta viene dada por el propio tratado constitutivo que concede la facultad de adoptar actos de contenido obligatorio de aplicación inmediata.

El derecho comunitario, surgido como resultado del traslado de competencias en diferentes materias del quehacer normativo por los países miembros y las subsecuentes regulaciones expedidas por las autoridades comunitarias apoyadas justamente en tales competencias y atribuciones, ofrece la doble característica de un sistema preeminente o de aplicación preferencial frente al derecho interno de cada país miembro y con una capacidad de aplicación directa y eficacia inmediata, porque a las regulaciones que se expidan con arreglo al sistema comunitario, no es posible oponerle determinaciones nacionales paralelas que regulen materias iguales o que obstaculicen su aplicación, ni su eficacia puede condicionarse a la voluntad del país o de las personas eventualmente afectadas por una decisión. ${ }^{33}$

Ahora bien, el vacío de derecho positivo que llena la nada escasa jurisprudencia de la Corte Constitucional colombiana en materia de aplicación directa de actos de organizaciones internacionales, se soporta en los tratados constitutivos de

\footnotetext{
${ }^{32}$ Constitución Política de Colombia, numerales 16 del artículo $150^{\circ}$ y 10 del artículo $241^{\circ}$.

${ }^{33}$ Corte Constitucional. Sentencia C-228 de 1995.
} 
las organizaciones interestatales. En principio, toda decisión de los órganos decisorios será directamente aplicable salvo que su texto requiera de acto expreso de incorporación al derecho interno; en este supuesto, estaríamos frente a obligaciones non self-executing.

\section{La internacionalización del derecho constitucional como garante de los procesos de integración}

La integración latinoamericana se convierte en un eje central en los últimos procesos constituyentes de los países andinos. ${ }^{34}$ Empezando por la Constitución colombiana de 1991, donde se observan normas de apertura para hacer efectivos los procesos de integración, garantizando la cesión de competencias a órganos supranacionales y la recepción automática de decisiones comunitarias. Sin estas cláusulas de apertura, la integración acabaría por configurarse como una mera declaración de intenciones. Ahora bien, se trata de unas normas de apertura focalizadas en determinada integración regional, la latinoamericana, y que incorpora elementos de control y decisión democráticas dentro de la naturaleza de las nuevas constituciones. Es una dimensión de las constituciones económicas, la cual, en palabras de Uprimny, se optó abiertamente por vincular sus economías con las de sus vecinos; con ello, proclaman explícitamente su adhesión a los principios de integración latinoamericana. ${ }^{35}$

Estamos frente a un nuevo modelo de constitucionalismo latinoamericano, que si bien está en construcción, hace referencia a un cambio de paradigma en el constitucionalismo. Este nuevo constitucionalismo se ha convertido en práctica en América Latina a través de los últimos procesos constituyentes latinoamericanos, articulados mediante la convocatoria de una Asamblea y la directa ratificación popular. A través de estos procesos, se han legitimado constituciones que han buscado no sólo ser fiel reflejo del poder constituyente del demos, sino, a continuación, permear el ordenamiento jurídico y revolucionar el statu quo de sociedades en condiciones de necesidad.

Esto ha consagrado textos densos, complejos y extensos. En el campo internacional, desde la Constitución colombiana, primera en esta tendencia, es fácil apreciar una dinámica integradora radicalmente diferente a la prevista en las constituciones anteriores: el nuevo constitucionalismo latinoamericano

\footnotetext{
${ }^{34}$ Martinez, Rubén y Tremolada, Eric. "Integración latinoamericana: democracia y cláusulas de apertura en el nuevo constitucionalismo", en Eric Tremolada (Ed.), Los procesos de integración como factor de paz, Universidad Externado de Colombia, Bogotá, 2014, pp. 119-147.

${ }^{35}$ UpRIMNY, RodRIGo. "Las transformaciones constitucionales recientes en América Latina: tendencias y desafíos", en César Rodríguez Garavito (coord.), El derecho en América Latina. Un mapa para el pensamiento jurídico del siglo XXI, Siglo XXI, Buenos Aires, 2011, p. 116.
} 
plantea un compromiso con determinada integración, la latinoamericana, más amplia que la puramente económica, que plantea posibilidades reales de integración de los pueblos y que, en definitiva, intenta compatibilizar la necesidad de integración con un concepto recuperado de soberanía. ${ }^{36}$

En la Constitución Política de Colombia de 1991 se inauguran estas previsiones. Desde el preámbulo se observa que el pueblo, en ejercicio de su poder soberano, decreta, sanciona y promulga la Constitución de 1991 "comprometido a impulsar la integración de la comunidad latinoamericana”. Ya en el cuerpo, el artículo 9 determina que la política exterior de Colombia se orientará hacia la integración latinoamericana y del Caribe. El mandato constitucional de apostar por la integración latinoamericana se ve fortalecido por el artículo 227 de la Constitución:

El Estado promoverá la integración económica, social y política con las demás naciones y especialmente, con los países de América Latina $\mathrm{y}$ del Caribe mediante la celebración de tratados que sobre bases de equidad, igualdad y reciprocidad, creen organismos supranacionales, inclusive para conformar una comunidad latinoamericana de naciones.

Se trata de una previsión relacionada con la competencia del Congreso prevista en el artículo 150.16 de la Constitución, que si bien no se refiere expresamente a la transferencia competencial, sí lo hace frente al carácter supranacional de los organismos creados por los tratados internacionales. En particular, hace mención a la creación de una comunidad latinoamericana de naciones como objetivo final de la integración latinoamericana.

El compromiso por la integración latinoamericana se repite en el caso de la Constitución venezolana de 1999, conocida como constitución bolivariana, tanto por el contexto ideológico y político que la vio nacer como por su objeto. $\mathrm{Al}$ igual que la colombiana, la Constitución bolivariana, desde el preámbulo, se refiere de manera expresa al compromiso con la integración regional: el objetivo del pueblo venezolano es refundar la república para establecer una sociedad democrática, participativa y protagónica, multiétnica y pluricultural, uno de cuyos fundamentos es "la cooperación pacífica entre las naciones [que] impulse y consolide la integración latinoamericana”. De nuevo evidenciamos un mandato constitucional al gobierno constituido de cimentar la integración regional: "La República -determina el artículo 153 en su inicio-promoverá

\footnotetext{
${ }^{36}$ Viciano Pastor, Roberto y Martinez Dalmau, Rubén. "El nuevo constitucionalismo latinoamericano: fundamentos para una construcción doctrinal", Revista General de Derecho Público Comparado, No. 9, 2011, pp. 8-24.
} 
y favorecerá la integración latinoamericana y caribeña, en aras de avanzar hacia la creación de una comunidad de naciones, defendiendo los intereses económicos, sociales, culturales, políticos y ambientales de la región”. ${ }^{37}$

Por su parte, la Constitución ecuatoriana de 2008, como en los casos anteriores, en el preámbulo, hace una referencia explícita al compromiso del constituyente ecuatoriano con la integración latinoamericana: el pueblo soberano de Ecuador decide construir "un país democrático, comprometido con la integración latinoamericana -sueño de Bolívar y Alfaro-, la paz y la solidaridad con todos los pueblos de la tierra". La referencia en el preámbulo se traduce ya en el articulado en un capítulo completo de la Constitución dedicado a la integración latinoamericana. ${ }^{38}$

La Constitución prescribe que la integración, en especial con los países de Latinoamérica y el Caribe, sea un principio de las relaciones internacionales (artículo 416.11), además de un objetivo estratégico del Estado ecuatoriano (artículo 423). Esto obliga al Estado a "impulsar la integración económica, equitativa, solidaria y complementaria; la unidad productiva, financiera y monetaria; la adopción de una política económica internacional común; el fomento de políticas de compensación para superar las asimetrías regionales; y el comercio regional, con énfasis en bienes de alto valor agregado" (numeral 1).

Además, promueve "estrategias conjuntas de manejo sustentable del patrimonio natural, en especial la regulación de la actividad extractiva; la cooperación y complementación energética sustentable; la conservación de la biodiversidad, los ecosistemas y el agua; la investigación, el desarrollo científico y el intercambio de conocimiento y tecnología; y la implementación de estrategias coordinadas de soberanía alimentaria" (numeral 2). Por otro lado, persigue el fortalecimiento de "la armonización de las legislaciones nacionales con énfasis en los derechos y regímenes laboral, migratorio, fronterizo, ambiental, social, educativo, cultural y de salud pública, de acuerdo con los principios de progresividad y de no regresividad" (numeral 3).

Por otro lado, protege y promueve "la diversidad cultural, el ejercicio de la interculturalidad, la conservación del patrimonio cultural y la memoria común de América Latina y del Caribe, así como la creación de redes de comunicación y de un mercado común para las industrias culturales" (numeral 4). Propicia "la creación de la ciudadanía latinoamericana y caribeña; la libre circulación de las personas en la región; la implementación de políticas que garanticen

\footnotetext{
${ }^{37}$ Martinez Dalmau, Rubén. "La integración en el nuevo constitucionalismo latinoamericano", en Tremolada, Eric (ed.), Crisis y perspectiva comparada de los procesos de integración, Universidad Externado de Colombia, Bogotá, 2008, pp. 89-92.

${ }^{38}$ Véase el capitulo tercero del título VIII, "Relaciones Internacionales".
} 
los derechos humanos de las poblaciones de frontera y de los refugiados; y la protección común de los latinoamericanos y caribeños en los países de tránsito y destino migratorio" (numeral 5).

Asimismo, impulsa "una política común de defensa que consolide una alianza estratégica para fortalecer la soberanía de los países y de la región" (numeral 6). Por último, favorece "la consolidación de organizaciones de carácter supranacional conformadas por Estados de América Latina y del Caribe, así como la suscripción de tratados y otros instrumentos internacionales de integración regional" (numeral 7). Todo esto despeja el campo a las normas de apertura en la misma Constitución. Finalmente, el artículo 276 de la Constitución ecuatoriana determina que uno de los objetivos del régimen de desarrollo es garantizar la soberanía nacional y promover la integración latinoamericana, entre otras previsiones (numeral 5).

El único caso en el marco del nuevo constitucionalismo que no menciona la vecindad latinoamericana en el preámbulo es la Constitución boliviana; sin embargo, está suficientemente desarrollada en el articulado. En efecto, el artículo 265.1 de la Constitución boliviana de 2009 establece un mandato claro:

El Estado promoverá, sobre los principios de una relación justa, equitativa y con reconocimiento de las asimetrías, las relaciones de integración social, política, cultural y económica con los demás Estados, naciones y pueblos del mundo y, en particular, promoverá la integración latinoamericana.

Con todo, como veremos, el texto boliviano es la que con más fortaleza soluciona el problema de relación entre democracia y cláusulas de apertura constitucionales.

\section{Cláusulas constitucionales de apertura y control democrático en los países andinos}

Las constituciones andinas en vigor buscan soluciones a la tensión entre democracia y normas de apertura a través de dos métodos: formalmente, incorporar con claridad la opción por la integración regional en el texto constitucional, además de las suficientes cláusulas de apertura para legitimar los avances integradores; materialmente, estableciendo mecanismos de control y legitimidad democrática, principalmente los referendos. ${ }^{39}$

39 Martinez, Rubén y Tremolada, Eric. "Integración latinoamericana: democracia y cláusulas de apertura en el nuevo 
La apuesta de la Constitución colombiana por la integración latinoamericana va acompañada por una serie de cláusulas de apertura que implican la posibilidad de incorporación de derecho externo al ordenamiento jurídico colombiano. Pero, como afırma Reina, la labor de identificación de las cláusulas de apertura ha correspondido al juez constitucional. ${ }^{40}$ Esa actividad no puede ser discrecional, porque se circunscribe a lo previsto en la Constitución, pues es la propia norma fundamental la que permite esa nueva concepción de texto constitucional abierto.

La norma de apertura general en la Constitución colombiana encuentra en el artículo 150.16 cuando firma que "corresponde al Congreso hacer las leyes. Por medio de ellas ejerce las siguientes funciones [...] 16. Aprobar o improbar los tratados que el Gobierno celebre con otros Estados o con entidades de derecho internacional. Por medio de dichos tratados podrá el Estado, sobre bases de equidad, reciprocidad y conveniencia nacional, transferir parcialmente determinadas atribuciones a organismos internacionales, que tengan por objeto promover o consolidar la integración económica con otros Estados".

Debe observarse que la norma de apertura económica a través de la cual Colombia puede formar parte de los procesos de integración está condicionada por dos límites expresos incorporados en la propia Constitución. Por una parte, la que incorpora el propio artículo 150.16: los tratados de integración firmados por la república, para que puedan ser constitucionales y servir de mecanismo de apertura y transferir atribuciones a organismos internacionales (materialmente comunitarios, aunque la Constitución no utilice esta expresión) deben ser negociados y aprobados sobre bases de equidad, reciprocidad y conveniencia nacional. Por otra, deben tener por objeto la promoción o consolidación de la integración con otros Estados, pero fundamentalmente los que forman parte de la comunidad latinoamericana tal y como determina el preámbulo constitucional. ${ }^{41}$

La Constitución está específicamente privilegiando los tratados que crean organismos supranacionales, siempre que su objeto sea la integración económica,

constitucionalismo", op. cit., p. 137.

${ }^{40}$ Reina Garcia, Óscar Mauricio. "Las cláusulas de apertura o reenvío hacia fuentes externas previstas en la Constitución colombiana, como criterio para delimitar el contenido del bloque de constitucionalidad", Revista Derecho del Estado, No. 29, julio-diciembre, 2012, p. 210.

${ }^{41}$ De acuerdo con la jurisprudencia de la Corte Constitucional colombiana, en sentencias como la C-582/1999, el preámbulo de la Constitución de 1991 se integra en el concepto de bloque de constitucionalidad en sentido amplio. No obstante, como señala Reina Garcia, no sería preciso acudir a la noción de bloque para buscar un contenido que se encuentra en la misma Constitución, toda vez que el juez constitucional -en Sentencia C479/1992- ya ha considerado que el preámbulo es parte integrante de la misma. Véase: Reina Garcia, Óscar Mauricio. "Las cláusulas de apertura o reenvío hacia fuentes externas previstas en la Constitución colombiana, como criterio para delimitar el contenido del bloque de constitucionalidad", op. cit., p. 201. 
social y política con países de América Latina y el Caribe. Es decir, no sólo se orienta la política exterior del ejecutivo hacia una región en particular, sino que se pone énfasis en que esa política tienda hacia la integración. De ahí que sostengamos que el énfasis y la orientación de la política exterior colombiana tenga un señalamiento sistémico y expreso en el preámbulo, en el segundo parágrafo del artículo 9: "la política exterior de Colombia se orientará hacia la integración latinoamericana y del Caribe”. El citado artículo 150.16 y el 227 hacen parte del capítulo De las relaciones internacionales; promueven "la integración económica, social y política con las demás naciones y especialmente, con los países de América Latina y del Caribe". ${ }^{42}$

Respecto a la vigencia de los derechos, el artículo 93 de la Constitución colombiana dispone una primera cláusula de apertura de gran relevancia destinada a su protección desde el derecho internacional:

Los tratados y convenios internacionales ratificados por el Congreso, que reconocen los derechos humanos y que prohíben su limitación en los estados de excepción, prevalecen en el orden interno. Los derechos y deberes consagrados en esta Carta se interpretarán de conformidad con los tratados internacionales sobre derechos humanos ratificados por Colombia.

Como puede apreciarse, la segunda parte del artículo hace referencia a la interpretación de la Constitución democrática. Los criterios de interpretación están en relación no sólo con los tratados internacionales considerados por sí mismos, sino obviamente con los instrumentos de interpretación que estos pueden incorporar a través de las cortes internacionales correspondientes. Es el caso de la jurisprudencia del Tribunal Interamericano de Derechos Humanos en la aplicación del Pacto de San José. ${ }^{43}$

Pero lo realmente interesante es la posibilidad, autorizada por la propia norma fundamental ("norma de normas", en términos del artículo 4 de la Constitución), ${ }^{44}$ de incorporar normas con origen en el derecho internacional

${ }^{42}$ Nótese que hablamos de disposiciones expresas que están contempladas a lo largo de la Constitución Política, en el preámbulo y en los títulos I, VI y vII relativos a los principios fundamentales, a la rama legislativa y a la rama ejecutiva. TREMOLADA, ERIC. "Los organismos supranacionales en la Constitución colombiana: ¿una garantía para el derecho andino?", en Tremolada Álvarez, Eric (ed.), Crisis y perspectiva comparada de los procesos de integración, Universidad Externado de Colombia, Bogotá, 2008, pp. 95-113.

${ }^{43}$ De hecho, la Constitución hace una referencia particular a la jurisprudencia internacional respecto a la delimitación territorial del país en el primer párrafo del artículo 101: "Los límites de Colombia son los establecidos en los tratados internacionales aprobados por el Congreso, debidamente ratificados por el Presidente de la República, y los definidos por los laudos arbitrales en que sea parte la Nación".

44 "La Constitución es norma de normas. En todo caso de incompatibilidad entre la Constitución y la ley u otra 
cuya aplicación prevalece en el orden interno; esto es, se aplican con preferencia a la propia Constitución. Cabe tomar en cuenta que esta aplicación preferente sobre la propia Constitución sólo puede tener lugar en el caso de que se trate de un tratamiento más favorable para los sujetos de derechos porque, en caso contrario, el citado artículo 4 prohibiría esta aplicación. Se trata, por último, de un problema de aplicación y no de jerarquía, pues la posición de la Constitución como norma suprema del ordenamiento jurídico, por su proveniencia directa de la voluntad constituyente, no puede estar en discusión. ${ }^{45}$ A partir de este artículo, la Corte Constitucional colombiana identificó la primera cláusula de apertura, y que daría origen a la amplia jurisprudencia colombiana sobre el bloque de constitucionalidad. ${ }^{46}$

La norma general de apertura en la Constitución venezolana de 1999, en su artículo 153, es ya de avanzada redacción. Hace referencia tanto a las condiciones de integración como a la aplicación directa y preferente del derecho comunitario:

La República podrá suscribir tratados internacionales que conjuguen y coordinen esfuerzos para promover el desarrollo común de nuestras naciones, y que garanticen el bienestar de los pueblos y la seguridad colectiva de sus habitantes. Para estos fines, la República podrá atribuir a organizaciones supranacionales, mediante tratados, el ejercicio de las competencias necesarias para llevar a cabo estos procesos de integración [...] Las normas que se adopten en el marco de los acuerdos de integración serán consideradas parte integrante del ordenamiento legal vigente y de aplicación directa y preferente a la legislación interna.

La tensión entre normas de apertura y democracia se soluciona en el caso venezolano con la amplia posibilidad de realizar un referéndum que legitime la cesión de competencias. Se prevé en el segundo párrafo del artículo 73:

Los tratados, convenios o acuerdos internacionales que pudieren comprometer la soberanía nacional o transferir competencias a órganos supranacionales, podrán ser sometidos a referendo por iniciativa del

\footnotetext{
norma jurídica, se aplicarán las disposiciones constitucionales".

${ }^{45}$ Tremolada, Eric y Martinez Dalmau, Rubén. "Jerarquía constitucional y aplicación preferente del derecho de la integración. Elementos para la solución del posible conflicto entre derechos e integración", Revista Vniversitas, No. 128, Bogotá, 2014, pp. 383-409.

${ }^{46}$ Reina Garcia, Óscar Mauricio. "Las cláusulas de apertura o reenvió hacia fuentes externas previstas en la Constitución colombiana, como criterio para delimitar el contenido del bloque de constitucionalidad", op. cit., p. 29.
} 
Presidente o Presidenta de la República en Consejo de Ministros; por el voto de las dos terceras partes de los o las integrantes de la Asamblea; o por el quince por ciento de los electores o electoras inscritos e inscritas en el Registro Civil y Electoral.

El artículo 318 de la Constitución prevé la posibilidad, extraña en la integración económica latinoamericana, de que la moneda venezolana se sustituya por una moneda común latinoamericana: "En caso de que se instituya una moneda común en el marco de la integración latinoamericana y caribeña, podrá adoptarse la moneda que sea objeto de un tratado que suscriba la República”. Es claramente un paralelismo con el proceso europeo de unificación monetaria, ${ }^{47}$ y una norma de apertura que legitimaría desde la Constitución el avance hacia la integración monetaria regional.

También en el caso venezolano encontramos una previsión particular respecto a la protección de los derechos fundamentales. El artículo 23 determina:

Los tratados, pactos y convenciones relativos a derechos humanos, suscritos y ratificados por Venezuela, tienen jerarquía constitucional y prevalecen en el orden interno, en la medida en que contengan normas sobre su goce y ejercicio más favorables a las establecidas en esta Constitución y en las leyes de la República, y son de aplicación inmediata y directa por los tribunales y demás órganos del Poder Público.

Como se ha explicado en otra sede, en este artículo la Constitución venezolana confunde textualmente aplicación con jerarquía. ${ }^{48}$ Los tratados internacionales de derechos humanos más favorables para los sujetos de derechos son de aplicación preferente en el orden interno, pero no pueden contar con jerarquía constitucional porque es la propia Constitución la que otorga la legitimidad para la vigencia de estos tratados y su aplicación preferente. Con todo, lo interesante de la norma de apertura es la posibilidad que otorga a la aplicación directa de determinados instrumentos de derecho internacional de los derechos humanos, condicionada - no podía ser de otra manera- a su carácter "más favorable" a los derechos establecidos en la propia Constitución. La condición, por lo tanto, está en consonancia con la evolución de los derechos y la mejor búsqueda de su protección que determina la Constitución de 1999; la consecuencia es

\footnotetext{
${ }^{47}$ Martinez Dalmau, Rubén. "Lecciones de unificación monetaria europea y particularidades sobre la integración latinoamericana", Oasis, No. 12, 2007, pp. 433-450.

${ }^{48}$ Tremolada, Eric y Martinez Dalmau, Rubén. "Jerarquía constitucional y aplicación preferente del derecho de la integración. Elementos para la solución del posible conflicto entre derechos e integración", op. cit., pp. 400-402.
} 
clara: todos los jueces de la república y los órganos del poder público están vinculados por estos derechos, y deben aplicarlos sin reservas.

En el caso ecuatoriano, el citado artículo 423.2 de la Constitución de 2008 determina que el Estado debe favorecer la consolidación de organizaciones latinoamericanas y caribeñas de carácter supranacional. El concepto supranacionalidad supera el de cooperación intergubernamental y se introduce en la cesión de competencias en el marco del proceso de integración. Para ello, el artículo 419 establece la cláusula de apertura por la cual la ratificación o denuncia de determinados tratados requiere de aprobación previa de la Asamblea Nacional: entre otros, aquellos tratados que "comprometan al país en acuerdos de integración y de comercio" (numeral 6) y los que "atribuyan competencias propias del orden jurídico interno a un organismo internacional o supranacional" (numeral 7). Con anterioridad, la Corte de constitucionalidad debe realizar el correspondiente control de constitucionalidad del tratado (artículo 438.1).

La relación entre integración y normas de apertura se establece en el caso ecuatoriano en el artículo 420, que prevé la ratificación mediante referéndum popular. Tanto la iniciativa ciudadana como el presidente de la república pueden convocar el referéndum que, legitima democráticamente la fórmula integradora. De hecho, el propio artículo 420 determina que si un tratado es aprobado por referéndum popular, su denuncia requerirá este mismo procedimiento.

El ejemplo más claro de la apuesta ecuatoriana por la integración latinoamericana se encuentra en el trato que dispensa la Constitución de 2008 a instancias de arbitraje contractual o comercial. El artículo 422 prohíbe "celebrar tratados o instrumentos internacionales en los que el Estado ecuatoriano ceda jurisdicción soberana a instancias de arbitraje internacional, en controversias contractuales o de índole comercial, entre el Estado y personas naturales o jurídicas privadas”. Sin embargo, el segundo párrafo del mismo artículo introduce una excepción:

Se exceptúan los tratados e instrumentos internacionales que establezcan la solución de controversias entre Estados y ciudadanos en Latinoamérica por instancias arbitrales regionales o por órganos jurisdiccionales de designación de los países signatarios.

Además de la norma genérica de apertura, la Constitución -como en el resto de cartas del nuevo constitucionalismo- introduce normas de apertura particulares, entre ellas la correspondiente a la aplicación directa de los "tratados internacionales de derechos humanos ratificados por el Estado que reconozcan derechos más favorables a los contenidos en la Constitución” y que prevalecen, 
con la Constitución, "sobre cualquier otra norma jurídica o acto del poder público" (artículo 424). ${ }^{49}$ El propio artículo 417 denomina cláusula abierta a esta previsión constitucional. Cabe también recordar la previsión ya mencionada del artículo 423.1 sobre la unidad productiva, financiera y monetaria latinoamericana.

Por último, en la Constitución boliviana de 2009, la cláusula de apertura se establece en el artículo 257.2 de la Constitución:

Requerirán de aprobación mediante referendo popular vinculante previo a la ratificación los tratados internacionales que impliquen:

1. Cuestiones limítrofes.

2. Integración monetaria.

3. Integración económica estructural.

4. Cesión de competencias institucionales a organismos internacionales o supranacionales, en el marco de procesos de integración.

A esto, cabe añadir la previsión sobre el bloque de constitucionalidad que se incorporó en los denominados Acuerdos de Cochabamba, y que están presentes en el artículo 410: "El bloque de constitucionalidad está integrado por los Tratados y Convenios internacionales en materia de Derechos Humanos y las normas de Derecho Comunitario, ratificados por el país".

La cláusula de apertura particular sobre los tratados internacionales de derechos humanos se encuentra en los artículos 216 y 13.4 de la Constitución boliviana:

Los tratados e instrumentos internacionales en materia de derechos humanos que hayan sido firmados, ratificados o a los que se hubiera adherido el Estado, que declaren derechos más favorables a los contenidos en la Constitución, se aplicarán de manera preferente sobre esta.

El segundo apartado determina: "Los derechos reconocidos en la Constitución serán interpretados de acuerdo a los tratados internacionales de derechos humanos cuando estos prevean normas más favorables”.

Por su parte, el artículo 13.4 incorpora un mandato particular relacionado con el anterior:

\footnotetext{
${ }^{49}$ A pesar de lo que pudiera parecer en un primer momento, el artículo 424 de la Constitución ecuatoriana no confunde jerarquía con aplicación en virtud del principio de jerarquia establecido en el artículo 425. TREMOLADA, ERIC y Martinez Dalmau, Rubén. "Jerarquía constitucional y aplicación preferente del derecho de la integración. Elementos para la solución del posible conflicto entre derechos e integración", op. cit., pp. 402-404.
} 
Los tratados y convenios internacionales ratificados por la Asamblea Legislativa Plurinacional, que reconocen los derechos humanos y que prohíben su limitación en los Estados de Excepción prevalecen en el orden interno. Los derechos y deberes consagrados en esta Constitución se interpretarán de conformidad con los tratados internacionales de derechos humanos ratificados por Bolivia.

Nótese que, como en casos ya analizados, su función no es sólo de innovación normativa, sino de interpretación constitucional.

\section{Conclusiones}

La interdependencia que impera en este mundo globalizado, donde la cooperación presupone la existencia de problemáticas y necesidades comunes, que usualmente se aborda a través de organizaciones interestatales y la protección de ciertos intereses esenciales, en razón de la solidaridad, limitan el concepto de soberanía del Estado y determinan la internacionalización del derecho constitucional.

La incorporación de normas internacionales en los ordenamientos internos dependerá del mecanismo de recepción previsto en las constituciones, según el mecanismo por el cual se creó la obligación. De ahí que la Constitución colombiana distinga cómo se reciben las normas de gestación consuetudinaria frente a las que son de origen convencional. Las normas consuetudinarias de derecho internacional humanitario y el derecho internacional general pasan a formar directamente parte del ordenamiento interno, mientras que todas las de origen convencional necesitarán antes de un acto legislativo expreso.

Además, las normas internacionales, según su contenido, una vez incorporadas, estarán al nivel de la Constitución o serán infra-constitucionales. Así, en Colombia, las normas de derecho internacional humanitario, sean de origen consuetudinario o convencional, integran el bloque de constitucionalidad, y todas las demás, de origen convencional, estarán sometidas a la Carta Política.

Asimismo, la ejecución en Colombia de normas internacionales convencionales o derivadas de organizaciones internacionales dependerá de su contenido; si prevén obligaciones de carácter general de Estado a Estado, que imponen un resultado o que contienen derechos imprecisos a favor de particulares, necesitarán la adopción de actos normativos internos. En caso de que regulen derechos y obligaciones concretos para los particulares, no necesitan medida interna de desarrollo (self-executing). 
Las constituciones andinas, que vienen construyendo un nuevo constitucionalismo latinoamericano, reconocen y desarrollan la primacía del derecho internacional general, el derecho internacional de los derechos humanos y la creación del llamado derecho comunitario o derecho de la integración.

Estas constituciones configuran un nuevo paradigma desde el punto de vista de la legitimidad y la solución de conflictos, al revisar el concepto arcaico de soberanía del Estado, permitiendo nuevas formas de colaboración en los marcos de integración, sobre todo la económica.

A diferencia del proceso de integración europeo, las nuevas constituciones latinoamericanas no sólo plantean la necesidad de legitimar formalmente, a través de las cláusulas de apertura, la recepción del derecho proveniente de órganos supranacionales o la cesión de competencias internas; lo quiere legitimar también, materialmente, a través de diferentes mecanismos, entre ellos la opción por la integración latinoamericana y la presencia de mecanismos de control y de decisión democrática, en particular los referendos. 